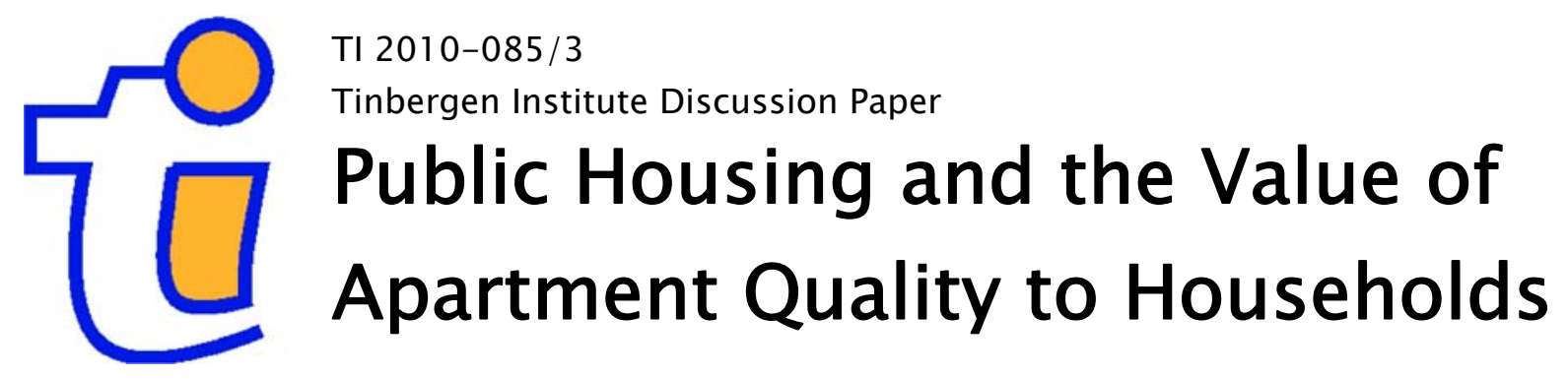

Jos Van Ommeren'
Marnix Koopman²

${ }^{\prime}$ VU University, Amsterdam, and Tinbergen Institute;

2 OTB Research Institute for Housing, Urban and Mobility Studies, Delft University of Technology, Delft. 


\section{Tinbergen Institute}

The Tinbergen Institute is the institute for economic research of the Erasmus Universiteit Rotterdam, Universiteit van Amsterdam, and Vrije Universiteit Amsterdam.

Tinbergen Institute Amsterdam

Roetersstraat 31

1018 WB Amsterdam

The Netherlands

Tel.: +31(0)205513500

Fax: $+31(0) 205513555$

Tinbergen Institute Rotterdam

Burg. Oudlaan 50

3062 PA Rotterdam

The Netherlands

Tel.: + $31(0) 104088900$

Fax: $+31(0) 104089031$

Most TI discussion papers can be downloaded at http://www.tinbergen.nl. 


\title{
Public housing and the value of apartment quality to households
}

\author{
Jos Van Ommeren* \\ VU University, FEWEB, De Boelelaan, 1081 HV Amsterdam, the Netherlands \\ Marnix Koopman \\ Delft University of Technology, OTB Research Institute for Housing, Urban and Mobility \\ Studies, Jaffalaan 9, 2628 BX Delft, the Netherlands
}

$8 / 27 / 2010$

\begin{abstract}
The application of hedonic price approaches to obtain estimates of the households' value of apartment characteristics is invalid for regulated housing markets such as public housing. We introduce and apply an alternative method that allows us to estimate renters' marginal willingness to pay for apartment characteristics based on residential mobility. We focus on the households' marginal willingness to pay for quality of apartments. We find that, on average, households place a monetary value on quality which is close to the non-profit housing associations' costs of providing quality.

JEL classification: $R 21$

Keywords: rent control, public housing, rental quality

${ }^{*}$ Corresponding author. E-mail address: jommeren@feweb.vu.nl. Jos Van Ommeren is affiliated with the Tinbergen Institute, Amsterdam. He would like to thank Netherlands Organisation for Scientific Research (NWO) for funding. Also he would like to thank Marcel Hoogzaad for valuable assistance, and Jaap de Vries and Aico van Vuuren for useful comments.
\end{abstract}




\section{Introduction}

In the current paper, we introduce, and apply, a dynamic search approach methodology to estimate the value of housing attributes to households in the public housing sector. In many large US and European cities, non-profit associations cover a large proportion of rental housing stock, usually labelled as 'public housing' in the US or as 'social housing' in Europe. It is estimated that about $46 \%$ of the rental market in the European Union (EU) is provided by non-profit associations. In the Netherlands, Austria, Denmark, and England, public housing is the dominant rental market form (Scanlon and Whitehead, 2007). In these countries, public housing is frequently similar to its form in the US in its earliest decades which focused on working class households. Empirical economic research on non-profit associations in the public housing market is absent despite its importance.

We consider the dynamic search approach as a suitable alternative to the standard static approach, which relies on estimation of hedonic price functions (see, e.g., Sheppard, 1999), and which may not be applied to the public housing sector where rents are either controlled or implicitly subsidised. This is an important restriction, because hedonic price estimates have been used on a large scale to estimate the value of non-market (dis)amenities such as pollution, parks etc, but these estimates do not apply to the households of public housing so the more disadvantaged households in society in which policymakers are particularly interested.

We focus on the Netherlands where about $85 \%$ of the rental units are supplied by a non-profit organisation (VROM, 2004). Large parts of the population live their whole lives in public housing. The large majority of public housing rental units are apartments, so, in the remainder of this study, we will refer to apartments.

One of the disadvantages of public housing - and housing market regulation, in general - is that housing suppliers' decisions, regarding the supply of rental quality, are distorted. For example, it is generally believed that private suppliers will under-invest in 
maintenance when faced with rent control. However, theoretical studies such as Olsen (1988) and Kutty (1996) show that the effect of rent control on rental quality is ambiguous. For example, Olsen (1988) shows that, if rent increases under a controlled regime are tied to landlord maintenance, rent control could lead to higher quality. The effect of rent control on rental quality has been empirically examined by at least a dozen studies. For reviews, see Moon and Stotsky (1993) and Sims (2007). Recent evidence by Sims (2007), which we believe is one of the most accurate studies, shows that rent control slightly reduces quality.

It is, a priori, not clear to what extent this result also hold for non-profit housing associations that all operate in a market with rent control and aim to keep rents 'affordable'. If these associations maximise welfare, then these associations will supply quality in accordance with the associated costs and the preferences of households and not reduce quality. We emphasise that, ceteris paribus, households will prefer higher quality, but since quality involves higher costs and higher rents, it is unknown whether non-profit associations under or oversupply quality.

To examine the allocation of rental quality for non-profit housing associations, we estimate the rent, costs, as well as the households' utility of quality (using the dynamic search approach) in the public housing sector, and examine whether the estimated households' willingness to pay for quality equals the costs of providing quality as one would expect in non-regulated markets.

In our empirical application, we focus on apartments owned by non-profit housing associations in Rotterdam, the second largest city of the Netherlands. Rents are controlled at the national level by restricting rent levels and by restricting annual increases. Rent levels depend on characteristics of the apartments including quality, see VROM (2007). Excess demand is dealt with using a queuing system based on the length of their residence duration. For most apartments, the waiting time is several years. Households that move into a new apartment lose their position in the queue as their residence duration is zero. Households are 
able to reject as many offers as they like (but are usually not allowed to inspect more than three available residences).

There are two distinctive characteristics of rent control in the Netherlands. First, because the controlled maximum rent depends positively on quality, housing associations have an incentive to provide quality, as demonstrated by Olsen (1988). Second, in contrast to private house suppliers that set the rent to the maximum value determined by rent control (Arnott, 1995), housing associations usually set rents slightly below the maximum value set by rent control (97\% of apartments in our sample), which offers even more freedom to set rents which depend on quality. ${ }^{1}$ One reason why associations do not ask the maximum rent is to justify the requirements of national governments, i.e., that they act in the interest of their tenants by providing affordable housing. Supply responses will be ignored. This is in line with Kangasharju (2008), which shows that public (but not private) housing providers set the rent in line with the costs.

To estimate the household's willingness to pay for quality, we introduce a dynamic search approach methodology for the housing market that employs information on the residential mobility of renters. It can be applied to regulated market, for example those with rent control and in the public housing sector. This approach acknowledges that in a regulated market, households search for apartments. The willingness to pay will be compared with the effects of quality on the apartment' rent and costs employing hedonic approaches.

\section{Theory}

\subsection{Theoretical model of residential moving}

Gronberg and Reed (1994) show for the labour market how a worker's marginal willingness to pay (MWP) for job attributes can be derived from job duration data, using a dynamic search approach methodology. In their approach, the trade-off between wages and job attributes is

\footnotetext{
${ }^{1}$ The rents do not depend on any characteristics of the renter though, as the rent is announced before applicants may apply. The only exception is that high income households pay the maximum rent, which we fully capture by a households income indicator.
} 
explicitly used. For empirical applications, we refer to, among others, Manning (2003a, 2003b) and Dale-Olsen (2006). We apply a similar approach to the rent-controlled housing market based on residential mobility, but the trade-off between rents and residential characteristics (viz quality) is used. ${ }^{2}$

Suppose that apartments are completely characterised by a (controlled) rent $r$ and a range of residential characteristics (e.g., quality). The residential characteristics are denoted as $s$. Suppose the presence of $\mathrm{N}$ residential characteristics, $s_{i}(\mathrm{i}=1, \ldots, \mathrm{N})$. Therefore, the household enjoys an instantaneous utility of an apartment, equal to $u$, where $u$ is a concave function of the rent $r$ and residential characteristics $s$. By assumption, the instantaneous utility is a negative function of the rent, so $u=u(r, s)$, where $u_{r}=\partial u / \partial r<0$.

Hedonic price theory relies on the assumption that house prices are set in a competitive market. In a competitive market, house suppliers ask a rent, (implicitly) taking into account that households maximise utility, have complete information, and may move residence at no costs. Households' maximisation of $u$ over $s$ indicates then that $u_{s}+(d r / d s) u_{r}=$ 0 , which implies that $d r / d s=-u_{s} / u_{r}$. Hence, in a competitive market, the marginal willingness to pay (MWP) for a residential characteristic, defined by $-u_{s} / u_{r}$, is equal to $d r / d s$. We will not make such an assumption. We will assume that the current rent may be determined arbitrarily and renters cannot freely move to other residences.

We assume that renters search for other (rent-controlled) apartments and receive offers of apartments, which arrive at a fixed finite rate $\lambda .^{3}$ Renters know the distribution of the utility of all other apartments in the market. Given an offer, renters have to immediately accept or reject the offer (usually referred to as a sequential search assumption). Thus, renters are not

\footnotetext{
${ }^{2}$ Bartik, Butler, and Liu (1992) derive the value of neighbourhood amenities using information about residential moving behaviour, but use a different methodology.

${ }^{3}$ This assumption, which must be interpreted as a simplification of the housing search process, is in line with the institutional setting of the regulated rental market in Rotterdam, where most apartments are allocated based on lotteries or queues. About two thirds of households that hold a residence in the public housing sector stay in this sector when moving residence.
} 
able to hoard (or recall) offers. Renters will accept an offer for another apartment, with a certain probability.

The assumptions regarding search technology seem to hold much better in the regulated rental market than in the labour market. For example, in the labour market, hoarding of multiple job offers (as well as recall) is not uncommon. In the regulated rental market, offers must be accepted upon inspection of the property. Hence, the sequential search assumption (which is strongly debated in the labour market literature) may hold almost literally in the regulated rental market. Let $\gamma$ denote the probability of acceptance. Renters will accept the offer if the utility associated with the offered apartment exceeds the level of the utility of the current apartment (taking future offers into account). This implies that the probability of acceptance will depend negatively on the utility of the current unit, so $\gamma=\gamma(u)$, where $\partial \gamma / \partial u<0$.

The exit rate, the rate at which the renter voluntarily leaves the current apartment, is denoted as $\theta$. So, $\theta=\lambda \gamma(u)$. We are particularly interested in the relationship between the ratio of the derivatives of the exit rate $\theta$ with respect to $r$ and $s$, and the ratio of the derivatives of the instantaneous utility function with respect to $r$ and $s$, which determines the negative of the marginal willingness to pay for characteristic $s_{i}$. Differentiation of $\theta$ as a function of $s_{i}$ and $r$, shows that these ratios are equal to each other:

$\frac{\frac{\partial u(r, s)}{\partial s_{i}}}{\frac{\partial u(r, s)}{\partial r}}=\frac{\frac{\partial \theta(r, s)}{\partial s_{i}}}{\frac{\partial \theta(r, s)}{\partial r}}$.

The left-hand side of this expression is the negative of the renter's MWP for a housing characteristic $s_{i}$. The right-hand side of the expression is the ratio of the marginal effects of characteristic $s_{i}$ and rent $r$ on the voluntary exit rate. 


\subsection{Discussion and extensions}

Some of the above assumptions may be restrictive, but they can be relaxed. For example, it may be assumed that the arrival rate $\lambda$ depends positively on the endogenously chosen search intensity $z$, and that the (time) costs of search are a positive convex function of $z$, which additively affects household utility. This extension takes into account that households may differ in their search intensity in the rental market.

Another assumption is that the arrival rate $\lambda$ is time-varying. This is relevant for rentcontrolled markets, where queuing systems are used to select renters so the offer rate, $\lambda$, is increasing over queuing time. So, another extensions is that $\lambda=\lambda(\tau)$, where $\tau$ is the time in the queue. This is relevant because in Rotterdam, households enter a new queue when they move residence, so $\tau$ is the elapsed residence duration. ${ }^{4}$ Another extension is the presence of residential moving costs (although for renters the moving cost usually thought to be small).

Given these three extensions, it can be shown that (1) still holds, see Van Ommeren, Van den Berg, and Gorter (2000) for details. ${ }^{5}$

The dynamic search approach to estimate the value of attributes is based on two fundamental assumptions. Arguably, both assumptions are more likely to hold in the rentcontrolled public housing market than in the labour market. First, application of the methodology in the labour market requires that the wage is set unilaterally by the employer, which does not allow for wage bargaining. In contrast, in the rent-controlled housing market, bargaining over the rent level is not possible. Second, involuntary residence moving in the Dutch rent-controlled market is non-existent as the duration of all rent contracts is infinite. In the labour market, involuntary job moving occurs regularly which may be problematic for some applications (see Van Ommeren and Hazans, 2008). In addition, heterogeneity in jobs is likely much larger than heterogeneity in residences (as jobs rely on social relationships that are unique

\footnotetext{
${ }^{4}$ Hence, in the empirical analyses we will control for the elapsed residence duration.

${ }^{5}$ Note however that the interpretation of (1) slightly changes when one allows for residential moving costs as the MWP is now based on the lifetime utility rather than the instantaneous utility. For the current application, this difference has no consequences.
} 
in nature, e.g., with colleagues), which makes it much more difficult to apply any ceteris paribus condition in the labour market than in the rent-controlled market.

\subsection{Welfare analysis}

Welfare analysis of models with search imperfections is non-standard, and has received much attention in the theoretical labour market literature (e.g., Hosios, 1990). For the labour market, it is generally believed that search imperfections are intrinsic (due to a lack of information about other agents in the labour market). This makes welfare analysis not only complicated, but also makes it dependent on difficult-to-verify conditions. In the rent-controlled, regulated housing-market, welfare analysis is straightforward, because search imperfections are not intrinsic, but induced by rent control that creates excess demand, such that queuing systems and other non-pricing mechanisms are created. So, the standard equilibrium condition that $d r / d s=-u_{s} / u_{r}=c_{s}$ applies, where $c_{s}$ denotes the marginal costs of providing residential characteristic $s$. Thus, the marginal rent equals the MWP, as well as the marginal cost of characteristic $s$.

In a regulated housing market, the above condition may not hold. For example, it may be the case that $-u_{s} / u_{r} \neq d r / d s=c_{s}$. Housing associations will then set marginal rents in accordance with marginal costs, but this is not optimal from a welfare perspective, because the supply of characteristic $s$ is not consistent with the preferences of households. Another relevant example is where $-u_{s} / u_{r}=c_{s} \neq d r / d s$. Hence, the willingness to pay for a characteristic equals the cost of providing that characteristic, but the marginal rents are not equal to the marginal costs.

It is then particularly interesting to focus on the case of a quasi- linear utility function where the demand for $s$ is independent of household income. In this case, despite rent control, households consume the optimal quantity of residential characteristics $s$ from a welfare perspective, although they consume off their demand curve (the households' welfare is then 
only affected through a lump-sum transfer induced by the difference between marginal rents and marginal costs).

\section{Empirical approaches}

\subsection{Estimation of marginal willingness to pay}

We aim to estimate $\left(\partial \theta / \partial s_{i}\right) /(\partial \theta / \partial r)$, that is, the ratio of the marginal effects of characteristic $s_{i}$ and rent $r$ on the residence exit rate $\theta$. We write $\theta$ as a function of observed determinants $x$, where $x$ includes apartment characteristics $s_{i}$ such as quality, the level of rent, and control variables (e.g., household income, neighbourhood dummies). A common specification, which guarantees that $\theta$ is positive, is that:

$\theta=\exp \left(x^{\prime} \beta\right)$

We will use the logarithm of rent, $\log r$, as a determinant, in $x$ (other functional forms generate similar results). Let $\beta_{i}$ denote the element corresponding to variable $x_{i}$. So, $\beta_{\text {logr }}$ denotes the coefficient of $\log r$. The MWP for $s_{i}$ equals then:

$$
M W P_{s_{i}}=-\frac{\beta_{i}}{\beta_{\log r}} r, \quad i=1, \ldots, n
$$

Hence, to calculate the MWP for apartment characteristics $\mathrm{s}_{i}$, it is sufficient to estimate the $\beta$ 's of the exit rate $\theta$. In our application, we employ data regarding the number of annual residential exits within a three-year period, so we observe $0,1,2$, or 3 exits. The appropriate stochastic model to use is a count model. In this model, the mean number of exits is captured by the parameter $\theta$, where $\theta$ is specified as in equation (2). We employ a negative binomial regression model, which encompasses the well-known Poisson regression model (Cameron 
and Trivedi, 1998; Winkelmann, 2003). ${ }^{6}$ In this model, $\beta$ has a straightforward interpretation, because $\beta=\partial \log \mathrm{E}(\mathrm{n}) / \partial \mathrm{x}$, where $\mathrm{E}(\mathrm{n})$ is the expected number of exits. In negative binomial models, unobserved heterogeneity is captured by one (positive) parameter $\alpha$, that allows for correlation between units of measurement. In one specification, unobserved apartment heterogeneity is accounted for by a parameter labelled $\alpha$ (apartment). In another specification, we capture unobserved building heterogeneity by a parameter labelled $\alpha$ (building).

\subsection{Estimation of costs and rents}

The marginal rent of apartment characteristics (e.g. quality) will be derived from a hedonic analysis with, as dependent variable, the logarithm of rent, $\log r$. We emphasise that the rent is regulated and should therefore not be interpreted as a equilibrium outcome of demand and supply. The marginal costs of these characteristics will be derived from a hedonic property price analysis, using the logarithm of the apartment's property value as a dependent variable. This is a valid approach, because apartments are freely traded in the ownership market. In the hedonic analysis of prices and rents, we will account for correlation between the error terms of apartments located within the same building.

\section{Empirical application}

\subsection{The data}

Our analysis is based on information about 9,146 rental units of 1,476 buildings during 2002, 2003, and 2004, obtained from non-profit housing associations in Rotterdam. For each rental unit, we know whether a rental unit has been vacated (at least once) during a certain year. When the rental unit is vacated, then this implies that the renter has moved residence. ${ }^{7}$ The

\footnotetext{
${ }^{6}$ The Poisson regression model is usually too restrictive for count data. For our sample, the Poisson regression model generates virtually identical estimates.

${ }^{7}$ A substantial proportion of renters may not have moved residence, but may have died, as the average age of the household head is 55 years. Because death is exogenous, and we control for age, this does not affect our estimates.
} 
frequency of the number of moves within the three-year period is given in Table 1 . We observe 1,990 annual moves. The average annual moving rate is $7.1 \% .^{8}$

Table 1. Number of moves, 2002-2004.

\begin{tabular}{crc} 
& Number of observations & Frequency \\
\hline 0 & 7,289 & 79.7 \\
1 & 1,728 & 18.9 \\
2 & 125 & 1.4 \\
3 & 4 & 0 \\
\hline Total & 9,146 & 100.0
\end{tabular}

Household characteristics are observed in 2002 only. We use these characteristics as time-invariant household characteristics. ${ }^{9}$ Households that occupy rental units are usually far from representative of the population. This is particularly true for cities where low-income households seldomly own apartments and where one has to wait many years before one has access to the rent-controlled market, so apartments are usually rented by elderly households. In our data, for $99 \%$ of households, the age of the household is above 28 years and their gross household income is below a government-defined threshold value, which determines whether households are categorized as poor ( $€ 15,725$ for single-person households, plus $€ 1,275$ if the head's age is below 65 , plus $€ 3,500$ for multi-person households). These households belong to the poorest $43 \%$ of households in Rotterdam. The average rent level is $€ 374$ per month. The average property price of the apartments they occupy is $€ 116,000$.

In our application, we control for a large number of apartment characteristics. Descriptives of the variables can be found in Table A.1 of the Appendix. For example, we

\footnotetext{
${ }^{8}$ This measure slightly underestimates the number of moves, as multiple moves within one year are only counted once. Given an average annual moving rate of $7.1 \%$, the annual moving rate is $0.22 \%$ higher than reported.

9 This creates measurement error in $14.2 \%$ of the observations. Excluding annual observations of rental units after a residential move, and estimating the annual probability of moving, generates almost identical results.
} 
control for the number of rooms, and the size in square meters. Further, we control for the residence duration of the household in 2002, and an indicator of household income. We also control for the age of the head-of-household. The effect of age on moving has been identified previously in other studies, usually suggesting that moving falls with age (Henley, 1998). In our sample, the mean (and the median) age of the household head is about 55 years. We also include neighbourhood controls. These neighbourhoods are small and the average distance to the centroid of a neighbourhood is less than 400 metres.

Further, we control for the property price residual from a standard hedonic price analysis (see column (2) of Table 3). The property price is based on the tax authorities' estimates, and may be interpreted as the market house price. ${ }^{10}$ The property price residual essentially captures unobserved local amenities of the apartment, such as the presence of shops, public transport, views, etc. Controlling for these amenities is particularly relevant for obtaining non-biased results regarding the effect of the rent, because a higher rent is likely associated with unobserved amenities that are positively valued by households. To control for the price residual rather than the price itself (which is more common) has no effect on the estimated willingness to pay for rental quality, the effect we are most interested in, but facilitates interpretation of the effect through unobserved amenities.

In order to derive the willingness to pay for rental quality, we include the logarithm of the monthly rent, in line with equation (3). The level of apartment quality is reported by the housing association in terms of discrete levels of maintenance, so we avoid subjective or strategic reports on quality by households, which is common in household surveys that analyse residential mobility. We distinguish between high-quality, average-quality and lowquality apartments. About $7 \%$ of the apartments are of high quality and $6 \%$ are of low quality. There is hardly any variation of quality of apartments within the same building (as maintenance occurs for the whole building, and not for individual apartments).

\footnotetext{
${ }^{10}$ Arguably, observations of house prices are biased, as the house prices reflect the effect of rent control in the neighbourhood. In the current paper, this issue is accounted for by using neighbourhood fixed effects.
} 
Table 2. Negative binomial regression of residential moving counts.

\begin{tabular}{|c|c|c|c|}
\hline & (1) & (2) & (3) \\
\hline rent level (in log) & $4.390(0.221)$ & $4.412(0.225)$ & $4.983(0.227)$ \\
\hline low rental quality & $0.352(0.121)$ & $0.322(0.119)$ & $0.416(0.124)$ \\
\hline high rental quality & $-0.312(0.131)$ & $-0.278(0.129)$ & $-0.458(0.146)$ \\
\hline residual of log property price & $-2.100(0.235)$ & $-2.086(0.229)$ & $-2.119(0.224)$ \\
\hline age & $-0.068(0.031)$ & & $-0.079(0.027)$ \\
\hline $\operatorname{age}^{2} / 1000$ & $0.114(0.492)$ & & $0.102(0.440)$ \\
\hline $\operatorname{age}^{3} / 100,000$ & $0.284(0.247)$ & & $0.288(0.222)$ \\
\hline log residence duration & $0.231(0.112)$ & & $0.250(0.101)$ \\
\hline $\log$ residence duration ${ }^{2}$ & $-0.014(0.015)$ & & $-0.014(0.139)$ \\
\hline high income & $0.206(0.218)$ & & $0.127(0.165)$ \\
\hline apartment without lift (no gr. fl.) & $0.352(0.079)$ & $0.427(0.079)$ & $0.376(0.090)$ \\
\hline apartment with lift (no gr. fl.) & $-0.195(0.103)$ & $-0.195(0.102)$ & $-0.016(0.110)$ \\
\hline size $\leq 50$ & $1.532(0.201)$ & $1.628(0.196)$ & $1.702(0.187)$ \\
\hline $50<$ size $\leq 60$ & $0.585(0.158)$ & $0.627(0.155)$ & $0.715(0.149)$ \\
\hline $60<$ size $\leq 70$ & $0.243(0.125)$ & $0.251(0.123)$ & $0.371(0.119)$ \\
\hline 1 room & $2.450(0.282)$ & $2.650(0.279)$ & $2.849(0.251)$ \\
\hline 2 rooms & $1.055(0.216)$ & $1.065(0.213)$ & $1.138(0.200)$ \\
\hline 3 rooms & $0.800(0.172)$ & $0.838(0.170)$ & $0.943(0.163)$ \\
\hline 4 rooms & $0.285(0.143)$ & $0.288(0.142)$ & $0.397(0.137)$ \\
\hline construction year $\leq 45$ & $0.699(0.159)$ & $0.711(0.158)$ & $0.634(0.151)$ \\
\hline $45<$ constr. year $\leq 75$ & $1.417(0.203)$ & $1.508(0.200)$ & $1.481(0.192)$ \\
\hline $75<$ constr. year $\leq 90$ & $0.329(0.186)$ & $0.378(0.183)$ & $0.199(0.187)$ \\
\hline single family dwelling & $-0.663(0.132)$ & $-0.674(0.129)$ & $-0.630(0.132)$ \\
\hline neighbourhood controls (8) & yes & yes & yes \\
\hline$\alpha \times 10^{-2}$ (apartment) & $0.060(3.064)$ & $0.064(2.51)$ & 0 \\
\hline$\alpha$ (building) & 0 & 0 & $0.126(0.030)$ \\
\hline $\log \mathrm{L}$ & -4571.605 & -4637.295 & -4551.891 \\
\hline number of observations & 9,146 & 9,146 & 9,146 \\
\hline
\end{tabular}

Note: Standard errors between brackets. 
Table 3. Hedonic price and rent analysis.

\begin{tabular}{|c|c|c|}
\hline & $\begin{array}{c}(1) \\
\log r e n t\end{array}$ & $\begin{array}{c}(2) \\
\text { log price }\end{array}$ \\
\hline low rental quality & $-0.079(0.012)$ & $-0.028(0.011)$ \\
\hline high rental quality & $0.130(0.016)$ & $0.103(0.015)$ \\
\hline apartment without lift (no gr. fl.) & $-0.053(0.004)$ & $-0.087(0.004)$ \\
\hline apartment with lift (no gr. fl.) & $0.008(0.009)$ & $0.004(0.008)$ \\
\hline size $\leq 50$ & $-0.256(0.011)$ & $-0.259(0.010)$ \\
\hline $50<$ size $\leq 60$ & $-0.144(0.010)$ & $-0.155(0.008)$ \\
\hline $60<$ size $\leq 70$ & $-0.066(0.008)$ & $-0.086(0.006)$ \\
\hline 1 room & $-0.463(0.017)$ & $-0.500(0.014)$ \\
\hline 2 rooms & $-0.158(0.013)$ & $-0.196(0.011)$ \\
\hline 3 rooms & $-0.112(0.011)$ & $-0.115(0.009)$ \\
\hline 4 rooms & $-0.042(0.015)$ & $-0.048(0.008)$ \\
\hline construction year $\leq 45$ & $-0.042(0.015)$ & $-0.093(0.014)$ \\
\hline $45<$ constr. year $\leq 75$ & $-0.039(0.020)$ & $-0.131(0.018)$ \\
\hline $75<$ constr. year $\leq 90$ & $0.107(0.018)$ & $0.021(0.017)$ \\
\hline single family dwelling & $0.075(0.009)$ & $0.214(0.008)$ \\
\hline neighbourhood controls & yes & yes \\
\hline spatial correlation & 0.508 & 0.563 \\
\hline
\end{tabular}

Note: Standard errors between brackets. The estimates are essentially the estimated coefficients of a regression analysis, allowing for correlation in the error terms. Correlation is accounted for using a random effects estimator, which allows the error terms of apartments that are located within the same building to be correlated.

Our results rely on the assumption that the rent level and rental quality are both not correlated to any unobserved household characteristic. This seems a reasonable assumption particularly because rents are regulated. However, we emphasise that all apartment characteristics (e.g. number of rooms) included in the analysis are interpreted as control 
variables for any unobserved household characteristic (e.g. number of children). ${ }^{11}$ In the sensitivity analysis, we particularly focus on this issue.

Some households in our data receive a rent subsidy. We lack information about this subsidy. Rent subsidies are paid to households based on income and the rent paid, if households consume more housing than a minimal amount (Koning and Ridder, 1997). On average, the rent subsidy is about $14 \%$ of the rent. This suggests that the estimated effect of rent level is biased towards zero. This bias is likely negligible because the marginal effect of the rent subsidy on the exit rate is an order of magnitude smaller than the effect of the rent, because almost all households that receive a rent subsidy for their current apartment will receive about the same level of subsidy for other apartments offered to them. ${ }^{12}$

\subsection{Empirical estimates}

\subsubsection{Main results}

In Table 2, column (1), the estimated coefficients can be found. We focus on the effects of two determinants of residential mobility: the rent and rental quality (which are reported at the top of the table). In line with theoretical expectations, the effect of rent on residential mobility is positive, whereas higher rental quality reduces residential mobility. ${ }^{13}$

Recall that rent is measured in logarithm, so the estimated coefficient of rent (4.390) can be interpreted as an elasticity. Hence, the results indicate a rent elasticity of about four to five. This result can be easily interpreted when it is realised that we control for the (residual

\footnotetext{
${ }^{11}$ Apartment and household characteristics are strongly correlated to each other, also because housing associations match households to certain apartments. For example, households with (many) children usually occupy apartments with more rooms; ground floor apartments are occupied by the elderly etc.

${ }^{12}$ If we assume, for example, that the (awarding of the) subsidy is household-specific, but the level of subsidy is apartment-specific and proportional to the rent (consistent with the institutional setting), then the bias in the effect of the logarithm of rent is zero, because $\log ($ net rent $)=\log ($ rent-subsidy $)=$ $\log ($ rent $-\delta$ rent $)=\log (1-\delta)+\log ($ rent $)$, where $0<\delta<1$. Hence, the logarithm of the net rent is equal to the logarithm of the rent plus a (negative) constant. Hence, it is likely that the marginal effect of rent subsidy on residential mobility for the current apartment - and therefore any bias in the effect of the rent - is close to zero.

${ }^{13}$ We do not discuss the results for the control variables, which are plausible and in line with the residential mobility literature.
} 
of) property price, and that the ratio of rent to property price essentially varies between 0.0033 and 0.0055 (with a median of 0.0043 ). The estimates imply then that an increase in rent over it's relevant interval increases the residential mobility rate by a factor of about two, which seems quite plausible. This finding supports the assumption of empirical studies which claim that the effect of rents on residential mobility is finite, so monopsonistic power is an important element for private suppliers (see Gibbons and Manning, 2006). The results indicate that the exit rates of low-quality and high-quality apartments differ by about $70 \%$, suggesting that quality is a key indicator for households.

Based on the estimates presented in Table 2 and equation (2), we are able to calculate the willingness to pay for rental quality. The results indicate that households are willing to pay a rent increase equivalent to an increase of $8.0 \%$ (calculated as $0.352 / 4.390$ ) to move from a low-quality apartment to an average-quality one. The standard error is $2.1 \%$, which is estimated using the delta method (e.g., Goldberger, 1991). Furthermore, they are willing to pay a rent increase equal to $7.3 \%$ to move from an average-quality to a high-quality apartment. The difference in the willingness to pay for a high-quality and low-quality apartment is therefore $15.3 \%$ (with a standard error of $3.1 \%$ ). This difference amounts to about $€ 602$ per year. ${ }^{14}$ A hedonic property price analysis indicates that the costs between high-quality and low-quality apartments is $13.1 \%$ (see column (2) of Table 3 , because $0.103+0.028=0.131)$, which is close to the households' willingness to pay for this quality difference. Importantly, this strongly suggest that the market outcome for rental quality is rather efficient when apartments are supplied by non-profit of associations, in contrast to earlier studies for private suppliers, which seems to provide an economic rationale for the existence of non-profit associations when rents are controlled (see Glaeser and Shleifer (2001) who provide other rationales).

\footnotetext{
${ }^{14}$ One may also determine the households' monetary value of other indicators such as lifts. The results presented in Table 2 indicate that the monetary value households attached to a lift is $12.4 \%$ of the rent $((0.352+0.195) / 4.390)$, about $€ 495$ per year, which seems a reasonable result.
} 
In a perfectly-competitive rental market, rents reflect the willingness to pay for apartment characteristics. This is, of course, not the case in a regulated rent-controlled environment. However, in a regulated environment, a hedonic rent analysis is still useful, as it shows the relationship between households' rental expenditure and the apartment characteristics enjoyed by the households. A hedonic rent analysis (see column (1) of Table 3) shows that the corresponding rent decrease associated with low-quality housing is $7.9 \%$ of the rent, which is identical to the willingness to pay of $7.9 \%$, estimated using the residential mobility model, so the rent exactly reflects the value that households attached to rental quality. However, the rent difference between high-quality and low-quality is $21 \%$, whereas the difference in the households' willingness to pay is only $15 \%$, so households consume of their demand curve. Given a quasi-linear utility function where the demand for quality does not depend on income, the market outcome will then be optimal, otherwise the market may be distorted through income effects.

\subsubsection{Sensitivity analyses}

As emphasised above, we have examined to what extent it is important to control for household characteristics. This is relevant, because we include few, but main, household characteristics, so as a minimum one must know whether controlling for household characteristics is essential. The results show that controlling, or not controlling for household characteristics, does not affect the results (see column (2) of Table 2). ${ }^{15}$ Furthermore, as can be seen from the first column of Table 2, household characteristics have no statisticallysignificant effect on residential mobility when controlling for apartment characteristics. This is in line with the literature, which usually shows that household characteristics - except for

\footnotetext{
${ }^{15}$ In a separate analysis not shown here, we have analysed the elapsed residence duration of new tenants (540 observations). For this subsample, we observe a large number of household characteristics. This analysis can be interpreted as an analysis of residential moving given stationarity assumptions (Van den Berg, 1992). We find that household characteristics such as income and number of children have no effect on the elapsed duration when controlling for apartment characteristics. This also suggests that our approach, to use apartment characteristics as control factors, is sufficient to control for unobserved household characteristics.
} 
age, for which we control, and the presence of children, for which we do not control - have limited explanatory power of residential mobility (Henley, 1998). This result makes particular sense in the context of regulated markets, as we have seen that occupants in regulated housing markets are much more homogeneous (in terms of income, age) than the population as a whole.

Another way to examine the sensitivity regarding the inclusion of controls for the presence of children, which we do not observe in our data and which is likely the most relevant explanatory variable we do not control for, is to segment the analysis based on age. This is useful because only a very small proportion of elderly households still have children at home (in the Netherlands, most children have left their parents house before they are 25 years old). We have therefore estimated the same model for two subsamples based on age: older households (55+) and younger households (55-). Again we find that the results remain robust. So, controlling for children is not relevant in the current context where we are interested in the effect of apartment quality.

We find also a similar robust result using subsamples for households with belowaverage or above-average residence durations. Because residence duration is a good indicator of the arrival rate of new residences (as there is a queueing system in Rotterdam based on the residence duration), it suggests that our results are robust with respect to the residence arrival rate. As shortly explained at the end of section 3.1, we have also estimated a negative binomial model where we allow the moving rate to be correlated within buildings. The correlation effect is captured by a parameter $\alpha$ (building). The results are reported in the last column of Table 2. Again, we find that the results are robust.

Studies such as Bajari and Benkard (2005) emphasise that it is important to take heterogeneity of consumers into account. Equation (1) does not impose a homogeneous households' assumption, but the estimation procedure based on equation (2) restricts the coefficients $\beta$ to be identical for all households, implicitly imposing a homogeneity 
assumption. We have relaxed this assumption by allowing for random heterogeneity in coefficients of households occupying different buildings. In random coefficient models, one must restrict the number of random coefficients for computational reasons. We therefore allow only the two coefficients of main interest to become random. In all models, the estimated heterogeneity of the coefficient for rent is small relative to the mean effect, so heterogeneity in the rent coefficient can be ignored. The coefficient for rental quality appears to have some random variation, but the results remain essentially unaltered.

\section{Conclusion}

We have introduced, and applied, a dynamic search methodology to estimate the household's monetary value of the quality of apartments in the public housing sector. In this sector, rents are controlled, and apartments are supplied by non-profit housing associations rather than by private suppliers. Our main interest is to determine the household's willingness to pay for quality in the public housing sector, which has received much attention for the private housing sector, and to compare this measure with measures of the effect of quality on costs and rents. Our methodology to derive household's monetary value of the quality of the apartment is based on household's residential mobility and generates plausible results. Our estimates demonstrate that the households' monetary value of rental quality is about $15 \%$ of the rent level.

One of the main, and surprising, implications of our results is that the households' monetary value attached to quality of their apartments is about equal to the costs of providing quality, suggesting efficiency regarding provision of rental quality by housing associations in the public housing sector. This does not imply however that rental quality is priced as in a private market. Our results allow for the possibility that the household's price of quality exceeds its costs. 
Our results also do not imply that residential characteristics other than quality are also offered in line with households preferences. In particular if the controlled rent is not tied to certain characteristics (as is the case for residential location in the Netherlands), it is plausible that the market outcome for these characteristics is strongly distorted by rental control.

Our explanation for the apparent efficiency of the market outcome for apartment quality is that housing associations are non-profit organisations which have an incentive to supply quality in line with households' preferences. This suggests that the difference between non-profit organisations and profit organisations is essential in markets with rent control and that non-profit organisations may reduce some of the market distortions induced by rent control. 


\section{References}

Arnott, R. (1995), Time for revision on rent control, Journal of Economic Perspectives, 9, 99120.

Bajari, P. and C.L. Benkard (2005), Demand estimation with heterogeneous consumers and unobserved product characteristics: a hedonic approach, Journal of Political Economy, 113, 6, 1235-1275.

Bartik, T.J., J.S. Butler and J.T. Liu (1992), Maximum score estimates of the determinants of residential mobility: Implications for the value of residential attachment and neighbourhood amenities, Journal of Urban Economics, 32, 233-256.

Cameron, C. and P.K. Trivedi (1998), Regression Analysis of Count Data, Cambridge University Press.

Dale-Olsen, H. (2006), Estimating workers' marginal willingness to pay for safety using linked employer-employee data, Economica, 73, 99-127.

Gibbons, S. and A. Manning (2006), The incidence of UK housing benefit: evidence from the 1990s reforms, Journal of Public Economics, 90, 799-822.

Glaeser, E.L. and A. Shleifer (2001), Not-for-profit entrepreneurs, Journal of Public Economics, 81, 99-115.

Glaeser, E.L. and E.F.P. Luttmer (2003), The misallocation of housing under rent control, American Economic Review, 93, 1027-1046.

Goldberger, A.S. (1991), A Course in Econometrics, Harvard University Press, Cambridge, Massachusetts.

Gronberg, T.J. and W.R. Reed (1994), Estimating workers' marginal willingness to pay for job attributes using duration data, Journal of Human Resources, 24, 911-931.

Gyourko, J. and P. Linneman (1989), Equity and efficiency aspects of rent control: an empirical study of New York City, Journal of Urban Economics, 26, 54-74. 
Häckner, J. and S. Nyberg (2000), Rent-control and prices of owner occupied housing, Scandinavian Journal of Economics, 102, 311-324.

Henley, A. (1998), Residential mobility, housing equity and the labour market, The Economic Jo urnal, 108, 414-427.

Hosios, A.J. (1990), On the efficiency of matching and related models of search and unemployment, Review of Economic Studies, 57, 279-298.

Ito, T. (2007), Effects of quality changes in rental housing markets with indivisibilities, Regional Science and Urban Economics, 37, 602-617.

Kangasharju, A. (2008), Housing allowance and the rent of low income households, Discussion Paper 458, Government Institute for Economic Research, Helsinki, Finland

Koning, R.H. and G. Ridder (1997), Rent assistance and housing demand, Journal of Public Economics, 1-31.

Kutty, N.K. (1996), The impact of rent control on housing maintenance, Journal of Housing Studies, 11, 69-88.

Manning, A. (2003a), The real thin theory: monopsony in modern labour markets, Labour Economics, 10, 105-131.

Manning, A. (2003b), Monopsony in Motion, Princeton University Press.

Moon, C. and J. Stotsky (1993), The effect of rent control on housing quality change: a longitudinal analysis, Journal of Political Economy, 101, 1114-1148.

Olsen, E.O. (1988), What do economists know about the effect of rent control on housing maintenance?, Journal of Real Estate Finance and Economics, 1, 295-307.

Scanlon, K. and C. Whitehead (2007), Social housing in Europe, LSE, London.

Sheppard, S. (1999), Hedonic analysis of housing markets, in: P.C. Cheshire and E.S. Mills (Eds.), Handbook of Regional and Urban Economics Volume 3: Applied Economics, Chapter 41, pp. 1595-1635, Amsterdam: North Holland. 
Sims, D.P. (2007), Out of control: what can we learn from the end of Massachusetts rent control?, Journal of Urban Economics, 61, 129-151.

Van den Berg, G.J. (1992), A structural dynamic analysis of job turnover and the costs associated with moving to another job, The Economic Journal, 102, 1116-1133.

Van Ommeren, J.N., G.J. Van den Berg and C. Gorter (2000), Estimating the marginal willingness to pay for commuting, Journal of Regional Science, 40, 541-563.

Van Ommeren, J.N. and M. Hazans (2008), The workers' value of the remaining employment contract duration, Economica, 75, 116-136.

VROM (2004), Cijfers over wonen; Feiten over mensen, wensen, wonen, The Netherlands.

VROM (2007), Woningwaarderings-/puntenstelsel voor zelfstandige woningen, The Netherlands.

Winkelmann, R. (2003), Econometric Analysis of Count Data, Springer, Fourth Edition, Berlin. 


\section{Appendix}

Table A.1. Descriptives.

\section{Continuous variables}

rent level (euro per month)

rent level (in $\log$ )

Property price (in euro)

Property price (in log)

age of household head (years)

$\log$ residence duration

\section{Dummy variables}

$\begin{array}{lc}\text { low quality } & 0.058 \\ \text { high quality } & 0.073 \\ \text { apartment without lift (no gr. fl.) } & 0.233 \\ \text { apartment with lift (no gr. fl.) } & 0.414 \\ \text { size } \leq 50 & 0.191 \\ 50<\text { size } \leq 60 & 0.264 \\ 60<\text { size } \leq 70 & 0.380 \\ \text { high income } & 0.009 \\ 1 \text { room } & 0.018 \\ 2 \text { rooms } & 0.147 \\ 3 \text { rooms } & 0.403 \\ 4 \text { rooms } & 0.282 \\ \text { Construction year } \leq 45 & 0.201 \\ 45<\text { constr. year } \leq 75 & 0.385 \\ \text { single family dwelling } & 0.215 \\ & \\ & \\ & \end{array}$

S.D.

87

0.239

29,900

0.268

16.811

1.129 